\title{
Desenvolvimento de um Jogo Educacional sobre a Classificação dos Animais usando Realidade Aumentada Online
}

\author{
Fabrício Santos Flauzino, Claudio Kirner \\ Instituto de Matemática e Computação - Universidade Federal de Itajubá (UNIFEI) \\ Caixa Postal 37500903 - Itajubá - MG - Brazil \\ \{fabricioflauzino, ckiner\}@gmail.com
}

\begin{abstract}
Augmented reality has great potential to introduce innovation in education, especially with the students familiar with the technology. This work shows the development of an online augmented reality application related to animal classification. The artifact was presented to teachers and students and the results are presented showing that this technology appeals to be useful in education.
\end{abstract}

Resumo. A realidade aumentada tem grande potencial para introduzir a inovação na educação, principalmente com os alunos familiarizados com a tecnologia. Assim, este trabalho mostra o desenvolvimento de um aplicativo de realidade aumentada on-line, relacionado à classificação animal. $O$ artefato foi apresentado a professores e alunos e os resultados são apresentados, mostrando que essa tecnologia tem apelo para ser útil em educação.

\section{Introdução}

O trabalho de disseminação do conhecimento em um âmbito escolar, em uma análise superficial, não é uma atividade que envolve um alto grau de complexidade, pois, neste contexto, o educador deve ser especialista no domínio, no qual leciona, para assim poder replicar o conhecimento. Esta análise é feita, sem levar consideração algumas variáveis do processo educacional como: o contexto tecnológico, muito presente na vida dos alunos, e as diversas formas de aprendizagem (visual, auditivo ou cinestésico). Devido a estes aspectos, percebe-se que a tarefa educacional é extremamente árdua, visto que o docente deve ser abrangente, devido à variedade de características que o universo de alunos apresenta.

A utilização de artifícios computacionais, no auxílio aos profissionais que trabalham com o conhecimento, torna a atividade educacional ampla, mais atrativa e eficiente. Além disso, as tecnologias para jogos possuem uma ampla variedade de opções, que os tornam interessantes aos usuários, tais como: suporte a objetos em três dimensões, narrativas e interações com o mundo virtual. Neste contexto, a realidade aumentada (RA) contribui para que o uso de dispositivos computacionais seja mais amigável e dinâmicos pois há uma grande interação entre o mundo virtual e a realidade do usuário, sobrepostos em aplicações. Sendo assim, a realidade aumentada é uma ferramenta excelente para auxiliar a desenvolver o aprendizado. Contudo, o uso desse 
tipo de software ainda é mais frequente em aplicações publicitárias e comerciais, utilizando-se muito pouco de uma tecnologia tão rica no campo educacional.

Ademais, o uso de realidade aumentada para o desenvolvimento de conhecimento é importante, devido as suas características básicas de interação, concentração e movimentação, juntamente com o estímulo motivacional que é o envolvimento com uma tecnologia inovadora. Nesse contexto, o software FLARAS [Souza, R.C., Moreira, H.D.F e Kirner,C. 2012] possui uma biblioteca de funções, que são de grande auxílio na produção de aplicações dinâmicas e modernas, a serem demonstradas no decorrer deste projeto.

Na seção 2, são descritos os jogos computacionais com realidade aumentada, enquanto que, na seção 3, é mostrada a ferramenta de autoria de aplicações de realidade aumentada Flaras. Em seguida, a seção 4 descreve o assunto da aplicação e a seção 5 mostra a aplicação desenvolvida neste trabalho sobre classe de animais. A seção 6 discute a avaliação aplicada a alunos e educadores e, por último, a seção 7 conclui este trabalho.

\section{Jogo Educacional com Realidade Aumentada}

Ambientes multimídias em sala se tornaram uma alternativa muito interessante para estimular crianças e jovens imersos em mundo de tecnologias, contudo, em muitos momentos o educador não sabe empregar este recurso de maneira dinâmica e atrativa. Neste ponto o uso de ferramentas que proporcionam a hipermídia, como a realidade aumenta, auxiliam os professores pois.

Realidade aumentada é uma tecnologia muito utilizada por games e atividades comerciais, que possuem suporte financeiro de corporações. Contudo, algumas aplicações como a de perguntas e respostas com RA (P\&R-RA) [Kirner, C. 2011] foram desenvolvidas para o ambiente educacional. A aplicação P\&R-RA permite a interação do usuário com um jogo espacial tangível de perguntas e respostas, conforme o exemplo da Figura 1.

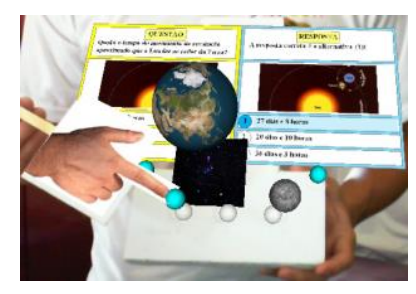

Figura 1. Aplicação P\&R-RA.

Neste exemplo (Figura 1), ao ativar um ponto, é exibida uma pergunta através de uma imagem com narração, aparecendo o questionamento: "Qual é o tempo do movimento de revolução aproximado que a Lua faz ao redor da Terra?”. Após a pergunta, o usuário pode ativar a exibição de uma animação em três dimensões, para melhor entendimento do problema. Em seguida, ao selecionar a resposta, o usuário pode validar sua opção. 


\section{Ferramenta de Autoria Flaras}

O Flaras (Flash Augmented Reality Authoring System) [Souza, R.C., Moreira, H.D.F e Kirner,C. 2012] é uma ferramenta para autoria de aplicações para uso online e local. A ferramenta foi desenvolvida sobre a biblioteca FlarToolKit [Saquosha. 2013], com licença de código aberto e disponível na internet, proporcionando um alto grau de interatividade, facilidade de desenvolvimento de artefatos e utilização pelo usuário final.

As aplicações são executadas diretamente de um navegador de internet, com o auxílio do adobe flash player, deixando a cargo do desenvolvedor de aplicações a escolha do meio em que será executada sua aplicação, podendo disponibilizá-la em um domínio da internet ou deixá-la para execução local.

Ao iniciar a aplicação, o usuário deve exibir o marcador de referência para a webcam, para que os pontos sejam listados na tela. A Figura 2c mostra um exemplo da interação do usuário com o Flaras. Nesse caso, foram desativados os pontos, clicando-se na lâmpada branca da barra inferior de funções da interface (marcada com um retângulo vermelho). Desta forma, torna-se mais fácil posicionar os pontos, sendo o contrário desta ação realizada na lâmpada amarela, que exibirá as cenas vinculadas aos pontos.

As funções do Flaras também permitem ativar e desativar a função de atração de pontos, mover, reiniciar, inverter a imagem da câmera, persistir a última posição do marcador, aumentar o tamanho dos pontos e modificar cenas, deixando o processo de desenvolvimento de aplicações menos complicado.
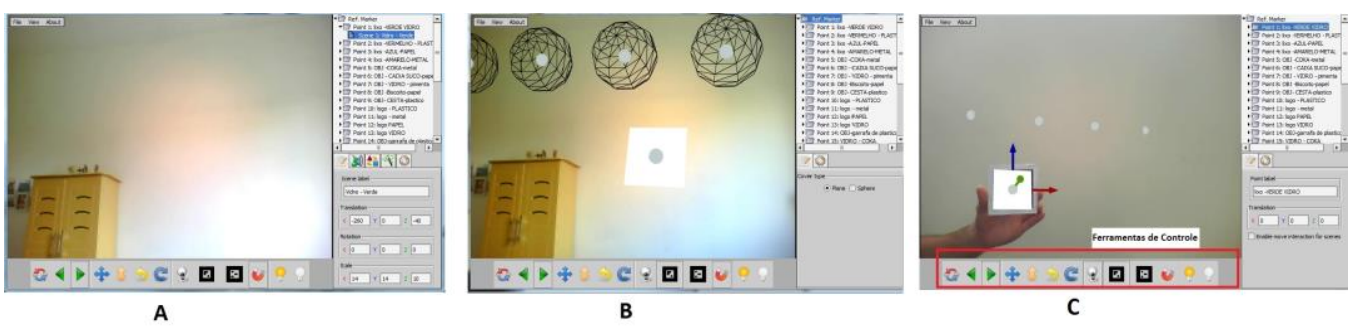

Figura 2. Flaras - Pontos.

Na Figura 2a, o usuário clicou sobre uma cena para assim poder realizar funções básicas de posicionamento (translação e rotação) e também modificar escala dos objetos. Todas as manipulações feitas na aplicação são feitas de maneira gráfica, este fato torna possível o uso do Flaras por não especialistas em programação.

O usuário pode ativar a função de persistência do marcador, permitindo que a aplicação permaneça na tela, mesmo com a retirada do marcador, como mostra a figura 2b. Assim, os pontos ficam estáticos, até que o usuário utilize o marcador novamente. Estão ativos também, na Figura 2b, os pontos de atração/repulsão, sob a forma de esferas pretas.

\section{Classe Animal}

A fim de tornar a aplicação mais adequada para alunos de ensino fundamental, o escopo da aplicação foi reduzido para abordar apenas quatro classes de animais: répteis, peixes, mamíferos e aves. Esta forma de classificação dos animais é adotada como forma 
didática para o ensino fundamental 1. Em Demétrio Gowdak e Eduardo Martins (2002) encontramos as definições básicas e concisas sobre cada classe.

\section{Desenvolvimento da Aplicação}

A aplicação é estruturada sobre conceitos básicos de associação, sendo que cada animal é atraído somente por sua classe e repelido pelas demais. A Figura 3a mostra um exemplo da utilização da aplicação, na qual pode ser notado que alguns animais estão dispersos pela tela e outros já estão atraídos por suas respectivas classes.

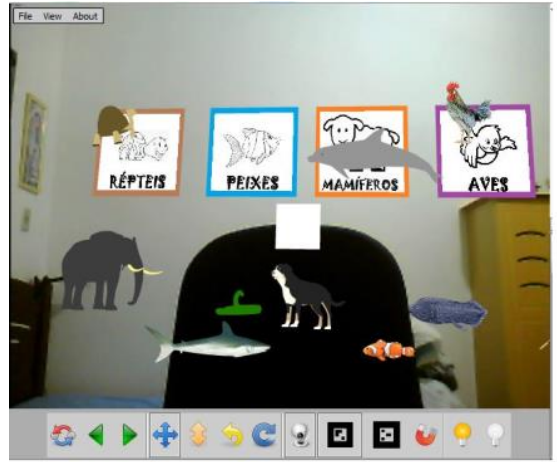

A) Aplicação Animal

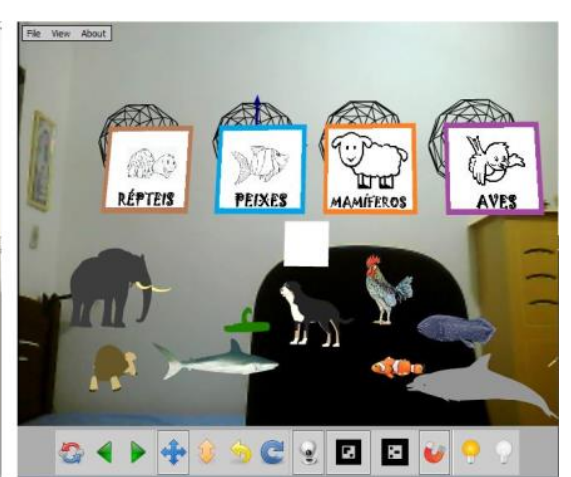

B) Esferas de Atração

Figura 3. A) Aplicação Classe Animal. B) Esferas de Atração.

O aluno irá clicar no animal e arrastá-lo, com o auxílio do mouse, até sua respectiva classe, que atrairá o animal ou o repelirá para sua posição inicial, dependendo da escolha ter sido certa ou errada. Toda ação realizada pelo aluno será acompanhada de um sinal sonoro que indicará o acerto ou erro da escolha realizada e informações sobre o animal selecionado.

Para realizar a tarefa de atrair ou repelir o animal sobre título de classe, inseriuse uma esfera de atração destinada a cada animal, de acordo com a definição que o animal possui, conforme Gowdak e Martins (2002). Para tanto, ao selecionar as esferas (Figura 3b), é possível associar cenas que serão atraídas por ela, sendo que, os outros animais não relacionados nesta lista serão repelidos.

Buscou-se transformar conceitos teóricos em uma atividade prática e dinâmica, com a facilidade da execução do conteúdo mesmo longe de um professor, dinamizando o processo educativo.

\section{Avaliação}

Realizou-se uma demonstração de conceitos de realidade aumentada e, em seguida, as aplicações desenvolvidas neste trabalho foram mostradas em uma instituição educacional, que, por normas internas, solicitou a não divulgação do seu nome. Esta instituição é filantrópica, e tem como regra um rigoroso processo seletivo, deste modo o ensino é ofertado somente a crianças incluídas em famílias com baixa renda.

A aplicação foi apresentada à comunidade escolar, em duas etapas. A primeira foi realizada durante uma reunião mensal de todo o corpo docente da unidade, em que 15 educadores ( 3 orientadores, diretor, 11 professores do ensino fundamental 1) foram submetidos a uma pesquisa, conforme a Tabela 1. Na segunda etapa, apresentou-se a 
aplicação e os conceitos de realidade aumentada para 80 alunos, com idade entre 9 e 11 anos, estudantes do ensino fundamental 1 e também os submetemos a um questionário descrito na Tabela 1.

Tabela 1. Avaliação aplicada aos alunos.

\begin{tabular}{|c|c|}
\hline \multirow{13}{*}{$\begin{array}{l}\text { Aplicação } \\
\text { Classe Animal }\end{array}$} & Características Analisadas - Educadores \\
\hline & 1. A aplicação Classe Animal pode ser um material de apoio útil ao ensino complementar. \\
\hline & 2. Os objetos da aplicação estão relacionadas ao cotidiano dos alunos. \\
\hline & 3. O ambiente é agradável para o aluno e o conteúdo está adequado para o ensino. \\
\hline & 4. O áudio é um complemento importante para a compreensão dos eventos. \\
\hline & $\begin{array}{l}\text { 5. O uso da aplicação Classe Animal facilita no processo de compreensão das diferentes classes de } \\
\text { animais. }\end{array}$ \\
\hline & 6. O tamanho dos objetos permite uma boa visualização e a interface gráfica é boa. \\
\hline & 7. As atividades propostas contribuem para o processo de ensino. \\
\hline & Características Analisadas - Alunos \\
\hline & 1. Este jogo deixa a aula mais interessante. \\
\hline & 2. Sei como separar animais de classes diferentes. \\
\hline & 3. Aprendi mais sobre classe animal através do jogo. \\
\hline & 4. Quero utilizar este jogo em minha casa. \\
\hline
\end{tabular}

Utilizou-se a escala de Likert [L.T. Brandalise], [R. Likert (1932)], com cinco posições, descritas na Tabela 2 , de forma que os educadores pudessem ponderar as afirmações feitas sobre as aplicações.

Tabela 2. Escalas adotadas para a avaliação.

\begin{tabular}{|l|l|l|l|l|}
\hline \multicolumn{5}{|c|}{ Escalas de Likert adotadas na avaliação } \\
\hline \multicolumn{1}{|c|}{5} & \multicolumn{1}{|c|}{4} & \multicolumn{1}{c|}{2} & \multicolumn{1}{c|}{1} \\
\hline $\begin{array}{l}\text { Concordo } \\
\text { Totalmente }\end{array}$ & Concordo Parcialmente & Indiferente & $\begin{array}{l}\text { Não Concordo } \\
\text { Parcialmente }\end{array}$ & $\begin{array}{l}\text { Não Concordo } \\
\text { Totalmente }\end{array}$ \\
\hline
\end{tabular}

Após a tabulação dos dados, percebeu-se que as informações obtidas estão tendendo para a concordância incondicional de todas as afirmações feitas, podendo este fato ser atribuído ao contato com uma tecnologia inovadora ou alguma falha no método escolhido para a pesquisa. Com isto, não há como fazer uma análise apurada das informações, apenas podemos ponderar algumas afirmativas e constatar que a aplicação pode ser ótima aliada ao processo de ensino, quando aplicada de forma auxiliar.

Na Figura 5a, observa-se que os resultados obtidos pela aplicação classe animal demonstra um alto nível de satisfação, dificultando até mesmo verificar possíveis falhas que a aplicação teria, no contexto educacional e de usabilidade. Sendo assim, a extração de informação crítica para melhoria da aplicação deve ser verificada novamente, após a presença efetiva da aplicação na rotina escolar. 


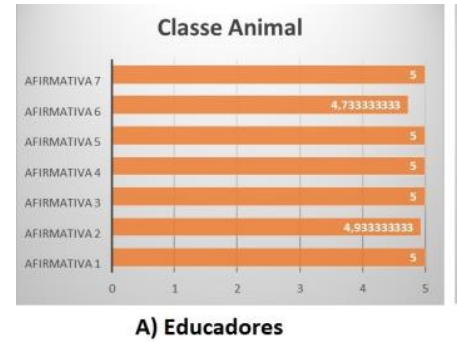

A) Educadores

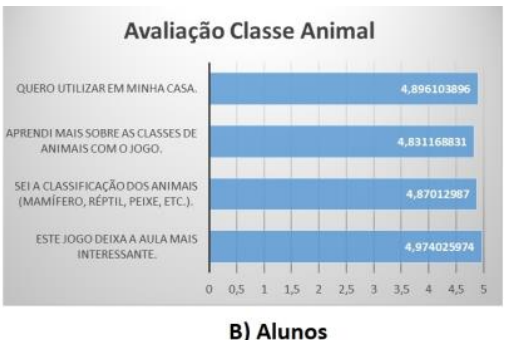

B) Alunos

Figura 5 A) Visão dos Educadores. B) Visão dos alunos.

A Figura $5 \mathrm{~b}$ mostra um alto nível de interesse dos alunos, sendo homogêneo o conjunto de resposta dos 80 alunos. Desse contingente aproximadamente $60 \%$ dos alunos possuem os requisitos mínimos para execução da aplicação, em vista que a instituição trabalha essencialmente com alunos de comunidades carentes. Essa é uma informação relevante, pois, pode-se dizer que esta aplicação poderá ser utilizada em seu propósito de material complementar, até mesmo em escolas com alunos de baixa renda. Assim este material pode ser utilizado em casa, como forma complementar do ensino tradicional, pois a aplicação é direcionada.

\section{Conclusão}

O projeto apresentou o desenvolvimento de uma aplicação, através da ferramenta de autoria de realidade aumentada FLARAS, que facilita e agiliza a criação de aplicações. O jogo foi avaliado por alunos e educadores do ensino fundamental 1, sendo obtido um retorno positivo durante a apresentação.

Ademais, notou-se também que esta aplicação traz ganhos educacionais aos alunos, quando aplicadas em paralelo a técnicas educacionais tradicionais de ensino. Isto ocorre, pois incluiu-se esse conteúdo educacional em um setor, onde os alunos já estão inseridos. Independentemente da classe social, esta geração de alunos já se encontra neste mundo de celulares, aplicativos e jogos.

\section{Referências}

Souza, R.C., Moreira, H.D.F and Kirner, C. (2012) "Flash Augmented Reality Authoring System", e-book. 2012. Disponível em: www.ckirner.com/flaras/download/documentacao/livro-flaras.pdf

Kirner, C. (2011) "Aplicação perguntas e respostas P\&R”, Disponível em: www.ckirner.com /sacra/PeR-RA.html

Saquosha. (2013) "FlarToolKir", Disponível em: http://saqoo.sh/a/flartoolkit/start-upguide

Demétrio Gowdak, Eduardo Martins. (2002) “Ciências Novo Pensar", São Paulo, $1^{\text {a }}$ Edição, Editora FTD.p. 60-124.

L.T. Brandalise, "Modelos de Medicação de Percepção e Comportamento: uma revisão". Relatório Técnico, Universidade Estadual do Oeste do Paraná UNIOESTE. Diponível em: www.lgtiufsc.br/brandilise.pdf.

R. Likert (1932) "A Technique for the Measurement of Attitudes, Archieves of Psychology” 140, pp. 1-55. 